\title{
Pre- and Post-Infection Activity of Pyraclostrobin for Control of Anthracnose Fruit Rot of Strawberry Caused by Colletotrichum acutatum
}

\author{
William W. Turechek, United States Department of Agriculture-Agricultural Research Service, Fruit Laboratory, \\ Beltsville, MD 20705; Natália A. Peres, University of Florida, Gulf Coast Research and Education Center, Wi- \\ mauma 33598; and Nicole A. Werner, Research Support Aide, Department of Plant Pathology, NYSAES, Cornell \\ University, Geneva, NY 14456
}

\begin{abstract}
Turechek, W. W., Peres, N. A., and Werner, N. A. 2006. Pre- and post-infection activity of pyraclostrobin for control of anthracnose fruit rot of strawberry caused by Colletotrichum acutatum. Plant Dis. 90:862-868.

The effect of pre- and post-infection-period applications of pyraclostrobin (Cabrio EG) on the development of anthracnose fruit rot was characterized in a controlled-climate study and validated in field studies in New York and Florida. Plants of the day-neutral cv. Tristar were inoculated with $C$. acutatum and placed into mist chambers at 14,22 , or $30^{\circ} \mathrm{C}$. The plants were removed from the chambers after 3, 6, 12, or $24 \mathrm{~h}$ of misting and placed on greenhouse benches to allow disease development. The fungicide pyraclostrobin was applied to the berries at a concentration equivalent to $168 \mathrm{~g}$ a.i./ha at $3,8,24$, and $48 \mathrm{~h}$ prior to inoculation and exposure to their wetting period, or $3,8,24$, and $48 \mathrm{~h}$ following inoculation and exposure to their wetting period. All pyraclostrobin treatments suppressed disease compared with the corresponding untreated control treatments. The highest incidence of disease occurred on plants exposed to the longest wetness durations $(12$ and $24 \mathrm{~h})$ or highest temperature treatments $\left(22\right.$ and $\left.30^{\circ} \mathrm{C}\right)$. Post-infection applications of pyraclostrobin provided significant control when applications were made within 3 and often up to $8 \mathrm{~h}$ after wetting, but generally were less effective than protective sprays. We further tested the ability of pyraclostrobin to control anthracnose when applied as a protectant or as an after-infection application in inoculated field plots exposed to a short ( $8 \mathrm{~h})$ or long ( $24 \mathrm{~h})$ wetting period in Florida and in New York. In three of the four experimental plots, disease control equivalent to or better than the protective spray was achieved when pyraclostrobin was applied up to $24 \mathrm{~h}$ after infection for long and short wetting periods. In the remaining plot, conditions for disease development were exceptionally favorable. The protective treatment provided approximately $75 \%$ control, whereas the best post-infection treatment provided only $50 \%$ control. Our study indicates that for short wetting events, such as those associated with seasonal thunderstorms, growers can wait until after such an infection event before applying pyraclostrobin and achieve control equivalent to a protective application.
\end{abstract}

Strawberry anthracnose, caused by $\mathrm{Col}$ letotrichum acutatum J. H. Simmonds, is one of the most serious diseases in commercial strawberry production. Even in well-managed fields, losses due to the fruit-rotting phase can exceed $50 \%$ when conditions favor disease development (10). Historically, the disease has been thought of as a "southern" disease (16), occurring primarily in the warmer production regions

Corresponding author: W. W. Turechek

E-mail: turechew@ba.ars.usda.gov

Mention of trade names or commercial products in this article is solely for the purpose of providing scientific information and does not imply recommendation or endorsement by the United States Department of Agriculture, University of Florida, or Cornell University.

Accepted for publication 5 February 2006

\section{DOI: 10.1094/PD-90-0862}

This article is in the public domain and not copyrightable. It may be freely reprinted with customary crediting of the source. The American Phytopathological Society, 2006. of North America. Over the last 20 years, however, losses due to anthracnose fruit rot have increased in fields across North America, including California, New York, Massachusetts, Pennsylvania, Ohio, and Ontario, Canada.

Although several species of Colletotrichum cause anthracnose on strawberry (6), C. acutatum is the most prevalent fruit-rotting pathogen. C. acutatum was first reported on strawberry in the United States in 1986 (25) and appears to be well established in the temperate and subtropical strawberry-growing regions in the United States. The fungus can attack virtually all parts of the plant, including the crown, leaves, petioles, and immature and mature berries (19), and also causes a root necrosis leading to stunting and chlorosis of the plant (5). The disease probably is introduced into plantings on contaminated nursery plants $(2,5,10)$. Once established, $C$. acutatum can overwinter under a wide variety of conditions in mummified fruit (31) or in soil with or without strawberry plant debris $(2-4,7)$. However, in warmer climates, it does not oversummer in asso- ciation with crown tissue (29). C. acutatum can survive and reproduce on the surface of leaves without causing symptoms through a process called microcyclic conidiation $(15,32)$. This means of survival may have serious implications for disease management because infested plants can escape inspection prior to planting and the pathogen may build up to high levels in the field undetected.

Conidia of $C$. acutatum are dispersed locally by splashing water, and droplets may be disseminated further with the aid of wind (33). A number of factors influence the efficiency of dissemination and the intensity of disease that results. Plastic ground cover facilitates the spread of disease manyfold relative to bare soil or straw mulch $(20,34)$. Yang et al. (34) showed that for plants grown on plastic mulch, as little as $15 \mathrm{~min}$ of rainfall was sufficient to achieve $100 \%$ infection of fruit lying within a $60-\mathrm{cm}$ radius of an infected source fruit. However, plastic ground cover is essential for weed management in annual production systems and its elimination is not a realistic option currently. In annual production systems, additional dispersal occurs when pickers spread spores from infected to healthy fruit when brushing their hands through the canopy searching for ripe fruit (16).

Wilson et al. (30) found that optimal temperatures for infection on immature and mature fruit were between 25 and $30^{\circ} \mathrm{C}$ on cv. Midway, with greater than $80 \%$ incidence occurring after $13 \mathrm{~h}$ of leaf wetness. They found that no infection occurred on immature or mature fruit below $4^{\circ} \mathrm{C}$, nor was any infection observed on immature fruit above $35^{\circ} \mathrm{C}$. Predictive curves for estimating the incidence of fruit infection as a function of the duration of berry wetness and temperature were developed and these adequately predicted infection in experimental field plots, with about $75 \%$ of the variation in disease incidence explained by these equations (20).

Most commercial management programs rely on calendar-based protective applications of fungicides for disease management. Under ideal management, fungicides would be applied only when necessary and, preferably, only in response to an infection event. However, this recommendation is difficult to follow, mainly because wetting events during fruit set and 
harvest are associated with sporadic thunderstorms that are difficult to predict. The degree of control that can be obtained with post-infection applications is difficult to predict because it is a function of the postinfection activity of the fungicide, the intensity of the infection event, and the application timing relative to the end of the infection event. To minimize the costs associated with the use of fungicides, an understanding of the conditions that favor disease development as well as knowledge of the efficacy of the available control options is required. The objective of this study was to quantify the efficacy of preand post-infection-period applications of pyraclostrobin on the development of anthracnose under different environmental conditions and assess the practical benefit of managing disease in response to infection events.

\section{MATERIALS AND METHODS}

Controlled-climate study. Plant production and maintenance. Plants of the day-neutral cv. Tristar were obtained from Nourse Farms (South Deerfield, MA). The plants were grown in 15 -cm-diameter pots in a 6:1 ratio of Cornell Mix (equal parts of peat moss and perlite) and sand and were deflowered for the first 6 to 8 weeks of growth to encourage uniform flowering and berry production. Bumblebees were introduced and utilized for pollination. The plants were watered once per week with a 50 ppm N solution, alternating weekly between Peter's calcium nitrate (15-0-0) and Peter's Peat-lite fertilizer (20-10-20 with micronutrients) as the nitrogen source (The Scotts Company, Marysville, $\mathrm{OH}$ ). Greenhouse temperatures were maintained at approximately $22^{\circ} \mathrm{C}$ and supplemental overhead light was used when necessary to encourage flowering.

Inoculum preparation and inoculation. A single isolate of $C$. acutatum was selected from a collection of isolates gathered from infected berries collected in commercial strawberry fields in New York in 2001. The isolate was selected based on its virulence relative to the other isolates collected. The isolate was identified based on conidial morphology and growth rate in culture relative to reference cultures of $C$. acutatum, C. gloeosporioides, and C. fragariae $(8,9,26,27)$. The isolate was maintained on potato dextrose agar with a 2.5 cm-diameter sterile strawberry leaf disk laid over the top of the medium to stimulate sporulation. The isolate was routinely inoculated and re-isolated from greenhouse-grown berries to ensure pathogenicity. Inoculum was prepared by flooding a petri dish containing an actively growing culture with sterile, deionized water, filtering the mixture through sterile cheesecloth into a flask with sterile, deionized water containing a single drop of Tween 20, and adjusting the final concentration to $2.5 \times$ $10^{4}$ conidia/ml (30). The conidial suspen- sion was applied to runoff directly to the berries with a handheld, hand-pressurized atomizer.

Fungicide treatments. Pyraclostrobin was applied directly to the berries with a 250-ml nonaerosol mister at a concentration equivalent to $168 \mathrm{~g}$ a.i./ha at $3,8,24$, and $48 \mathrm{~h}$ prior to inoculation and exposure to their wetting period (see below); these were defined as pre-infection or protective applications. Another set of plants was treated $3,8,24$, and $48 \mathrm{~h}$ following inoculation and exposure to their wetting period. These were designated as the post-infection-period treatments. Fenhexamid (Elevate 50 WDG, Arysta LifeScience, Cary, NC) was added to pyraclostrobin at the rate equivalent to $0.56 \mathrm{~kg}$ a.i./ha to control Botrytis cinerea; fenhexamid has no activity against $C$. acutatum (21).

Environmental conditions. Three temperatures and four durations of leaf wetness were combined in a factorial design to produce a range of environmental conditions for the development of anthracnose; the results of Wilson et al. (30) were used as a guide in selecting the environmental parameters. In all, 168 plants were placed in each of three walk-in mist chambers at 14,22 , or $30^{\circ} \mathrm{C}$ and $100 \%$ relative humidity (504 plants in each single replication). In each chamber, temperature was monitored with an alcohol thermometer as well as a HOBO Datalogger (Onset Computer Corp., Bourne, MA). Plants were misted within the chambers and removed in groups of 40 after wetting periods of 3, 6, and $12 \mathrm{~h}$ or in groups of 48 for the longest wetting period $(24 \mathrm{~h})$, moved to greenhouse benches, and dried with box fans. Plants were removed 15 min prior to the defined wetting period, and the drying time was added as part of the total wetting period.

Experimental design and statistical analysis. Experimental factors were arranged in a split-split plot design. Temperature served as the whole plot factor and the walk-in chamber was considered the experimental unit. Wetting period served as the subplot factor and fungicide treatment served as the sub-subplot factor. Four plants were selected arbitrarily at each temperature-wetting period combination and subjected to one of the nine pyraclostrobin treatments (i.e., one of the preor post-wetting period applications or an inoculated control). A single treatment of fenhexamid applied $3 \mathrm{~h}$ prior to inoculation was included at each temperaturewetting period combination to evaluate the effect of fenhexamid on anthracnose development. Noninoculated plants sprayed with pyraclostrobin and fenhexamid $3 \mathrm{~h}$ prior to inoculation and noninoculated plants without fungicide were included at the 24-h wetting period to monitor for any injury that may have resulted from the application of treatments or C. acutatum contamination. Three replications were done over time due to limitation in available chamber space and the size of the experiment.

The proportion of immature berries, mature berries, or the sum of the two (total berries) with anthracnose symptoms was calculated 6 to 10 days after inoculation for each treatment. Fruit were classified as mature if they were fully ripe at the time of rating. Immature berries included berries with or without red tinting, but excluded berries that were clearly too small to have been inoculated at the time of inoculation. The proportions were subject to the arcsine transformation and the data were analyzed as a generalized linear mixed model (GLMM) using the SAS procedure PROC MIXED (18). Temperature, wetness duration, and fungicide treatment were treated as fixed effects, whereas replication and its interactions with the main effects were treated as random effects. Treatment differences for the fixed effects were obtained using the pairwise difference option of PROC MIXED.

Field study. Planting sites. Research plantings were established at two locations. In New York, plantings of 'Jewel' and 'Kent' were established at the New York State Agricultural Research Experiment Station in Geneva, NY in May 2001. The plants were established in a mattedrow system from bare root runner plants obtained from Nourse Farms into a glyphosate-treated and cultivated field. Each planting was approximately 0.04 ha with 10 rows planted on 1.2-m centers. Research plots were established within each planting and individual plots within plantings consisted of $3.65-\mathrm{m}$ row segments with a $0.9-\mathrm{m}$ buffer section on each end.

In Florida, bare root runner plants of 'Camarosa' or 'Strawberry Festival' were transplanted into methyl bromide: chloropicrin (98:2)-fumigated soil in plastic-mulched raised beds in October 2003 and 2004, respectively. Transplants were irrigated by overhead sprinklers for 10 to 12 days to aid establishment, then irrigated and fertilized through drip tape. Each bed contained two staggered rows of plants spaced $38 \mathrm{~cm}$ apart within rows and $31 \mathrm{~cm}$ apart between rows. The beds were $71 \mathrm{~cm}$ wide on 1.2-m centers. Research plots were established within each planting and individual plots were $2.4 \mathrm{~m}$ long and contained 14 plants.

Experimental design and treatment application. The results of the controlledclimate study were used to select wetting regimes that would generate differential levels of anthracnose and application timings for disease management. Each planting was bisected to allow two separate wetting regimes that were designated as short ( $8 \mathrm{~h}$ of wetting) and long ( $24 \mathrm{~h}$ of wetting). Four fungicide treatments and an inoculated control were assigned to plots in each of the wetting regimes in a ran- 
domized complete block design. In Florida, pyraclostrobin was applied to the berries at a concentration of $168 \mathrm{~g}$ a.i./ha at 16 or $24 \mathrm{~h}$ prior to inoculation as the protective treatment for the short and long wetting periods, respectively. In New York, pyraclostrobin was applied $18 \mathrm{~h}$ prior to inoculation and exposure to the wetting period as the protective treatment. The differences in timing were chosen for convenience and because only marginal differences were expected with protective applications made within $24 \mathrm{~h}$ of inoculation. The post-infection treatments at both sites included pyraclostrobin applied at the same rate 4,8 , and $24 \mathrm{~h}$ following inoculation and exposure to the wetting period.

In New York, plots were inoculated on 8 June 2004 ('Kent') and 11 June 2004 ('Jewel') by preparing an inoculum suspension as above and evenly applying 8 liters to runoff to the entire planting using a 9.5-liter, hand-pressurized garden sprayer. Plots were overhead irrigated with a mist system that produced little splashing. In Florida, plots were inoculated on 11 March 2004 ('Camarosa') and 25 March 2005 ('Strawberry Festival') by placing three berries with sporulating anthracnose lesions equidistant from each other in each plot. The plantings were irrigated with overhead sprinklers which facilitated the spread of inoculum.

Data collection and statistical analysis. In New York, mature berries were harvested twice; first at 7 or 8 days after inoculation, and then 4 or 5 days later. In Florida, berries were harvested five times at 3- to 5-day intervals beginning 5 days after inoculation. The proportion of berries with anthracnose symptoms in each plot was recorded. The proportions were subject to the arcsine transformation and the data were analyzed as a GLMM using the SAS procedure PROC MIXED. Fungicide treatment was treated as a fixed effect and replication was treated as a random effect. Treatment differences for the fixed effect were obtained using the PDIFF option in PROC MIXED.
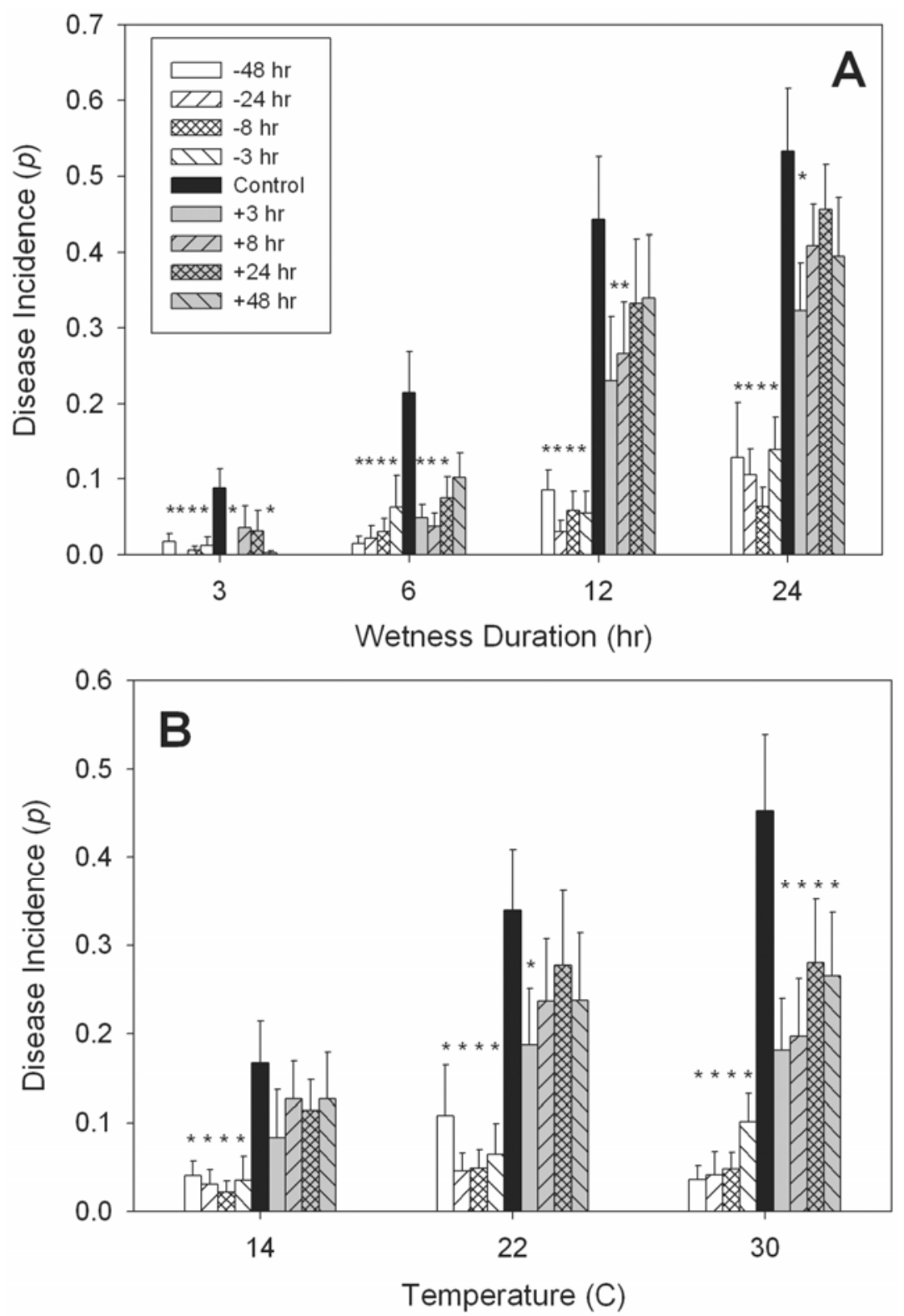

Fig. 1. Incidence and standard error of anthracnose on total strawberry fruit inoculated with Colletotrichum acutatum and treated with pyraclostrobin $3,8,24$, or $48 \mathrm{~h}$ before inoculation (bars with white background) or $3,8,24$, or $48 \mathrm{~h}$ after inoculation (bars with gray background) in a laboratory experiment after exposure to $\mathbf{A}$, $3,6,12$, or $24 \mathrm{~h}$ of wetting (averaged across the three temperature treatments) or $\mathbf{B}$, temperatures of 14,22 , or $30^{\circ} \mathrm{C}$ (averaged across the four wetting durations). The black bars show incidence of anthracnose in the untreated, inoculated controls. Asterisks indicate treatments that are significantly different from their corresponding control according to the PDIFF option of PROC MIXED $(P=0.05)$.

Table 1. Analysis of variance of the effects of application timing of pyraclostrobin, wetness period, and temperature on the incidence of anthracnose caused by Colletotrichum acutatum on immature berries, mature berries, and total berries in a controlled-climate study ${ }^{\mathrm{a}}$

\begin{tabular}{|c|c|c|c|c|c|c|c|}
\hline \multirow[b]{2}{*}{ Source } & \multirow[b]{2}{*}{ df } & \multicolumn{2}{|c|}{ Immature berries } & \multicolumn{2}{|c|}{ Mature berries } & \multicolumn{2}{|c|}{ Total berries } \\
\hline & & Mean square & $F$ value & Mean square & $F$ value & Mean square & $F$ value \\
\hline Replication & 2 & 0.1039 & $17.56^{*}$ & 0.5153 & 2.19 & 0.4976 & 1.36 \\
\hline Temperature $(\mathrm{T})$ & 2 & 0.5172 & $87.44 * *$ & 2.3051 & $9.80 *$ & 0.7786 & 2.14 \\
\hline Error $a$ & 4 & 0.0059 & & 0.2352 & & 0.3646 & \\
\hline Wetting (W) & 3 & 0.7453 & $32.77 * *$ & 4.988 & $44.29 * *$ & 3.1346 & $33.85 * *$ \\
\hline $\mathrm{T} \times \mathrm{W}$ & 6 & 0.1607 & $7.07 * *$ & 0.3669 & $3.26^{*}$ & 0.2619 & $2.83 *$ \\
\hline Error $b$ & 18 & 0.0227 & & 0.1126 & & 0.0926 & \\
\hline Fungicide $(\mathrm{F})$ & 8 & 0.1065 & $6.66 * *$ & 1.0963 & $18.92 * *$ & 0.8323 & $39.82 * *$ \\
\hline $\mathrm{F} \times \mathrm{T}$ & 16 & 0.0312 & $1.95^{*}$ & 0.0866 & 1.49 & 0.0488 & $2.33 * *$ \\
\hline $\mathrm{F} \times \mathrm{W}$ & 24 & 0.0587 & $3.67 * *$ & 0.1528 & $2.64 * *$ & 0.0905 & $4.33 * *$ \\
\hline $\mathrm{F} \times \mathrm{W} \times \mathrm{T}$ & 48 & 0.0258 & $1.60 *$ & 0.0530 & 0.91 & 0.0296 & 1.42 \\
\hline Error $c$ & 192 & 0.0159 & & 0.0579 & & 0.0209 & \\
\hline Total & 324 & $\ldots$ & $\ldots$ & $\ldots$ & $\ldots$ & $\ldots$ & $\ldots$ \\
\hline
\end{tabular}

a The study was designed as a split-split plot. For $F$ values, * and ** represent $P$ values of $<0.05$ and $<0.01$, respectively. 


\section{RESULTS}

Controlled-climate study. Disease incidence in the inoculated controls increased proportionally with temperature and leaf wetness and was similar to that predicted by Wilson et al. (30; see equations in their tables). The plants treated only with fenhexamid developed anthracnose to levels equivalent to the inoculated control plants (results not shown). A notable difference between the two studies was the lower incidence of anthracnose on immature berries at 22 and $30^{\circ} \mathrm{C}$ in our study. This may have been the result of our defining the maturity of berries differently than Wilson et al. (30). In our study, only fully ripened berries at the time of rating were considered mature, whereas all others were classified as immature. Wilson et al. (30) classified mature berries as those "beginning to turn red;" immature berries were those "beginning to lose chlorophyll and turn whitish." Another discrepancy was the lower incidence of anthracnose on mature berries exposed to $24 \mathrm{~h}$ of misting at $22^{\circ} \mathrm{C}$. The lower incidence may be the result of an inherently higher level of resistance to anthracnose in 'Tristar' relative to 'Midway'. The same reasoning also may explain differences observed with the immature berries.

The main effect factors of fungicide treatment and wetness duration had the largest impact on the incidence of anthracnose on mature and total berries (Table 1). Temperature had the greatest effect on the incidence of anthracnose on immature berries, a lesser effect on mature berries, and was not significant for total berries. The lack of a consistent temperature effect is a reflection of the narrow range of temperatures selected for this experiment. Temperatures were chosen within the range where disease was expected to develop and growers likely would consider applying a fungicide. Moreover, because temperature served as the whole-plot factor, the resulting $F$ test had the lowest power for detecting differences compared with the $F$ tests for the other main effects. The interaction of temperature with leaf wetness significantly affected the incidence of anthracnose on immature berries, mature berries, and total berries and was similar to that described by Wilson et al. (30). It was their description of this interaction that served as the basis for selecting the levels of temperature and leaf wetness in this experiment. In the remainder of this article, only the results from the combination of immature and mature berries (i.e., total berries) are shown because results across the three analyses were similar, and overall incidence was more reflective of responses encountered under field conditions.

There was a clear interaction between application timing and wetness duration as well as between application timing and temperature (Figs. 1A and B, respectively;
Table 1). The difference in anthracnose incidence between pre- and post-infection period applications of pyraclostrobin was most evident. When averaged across temperatures, post-infection period applications consistently suppressed anthracnose to levels below their corresponding control treatments only when applied within $3 \mathrm{~h}$ of the end of an infection period when the wetness duration was $24 \mathrm{~h}$ or less (Fig. 1A). When averaged across wetness durations, only pre-infection period applications consistently suppressed disease to levels significantly below their corresponding untreated controls (Fig. 1B). Applications of pyraclostrobin applied $3 \mathrm{~h}$ postinfection suppressed disease to levels below their corresponding control at 22 and $30^{\circ} \mathrm{C}$ but not at $14^{\circ} \mathrm{C}$. However, the incidence of anthracnose was low at $14^{\circ} \mathrm{C}$ (Fig. 1B).

When averaged across all combinations of temperature and wetting durations, there were clear differences between the preinfection-period applications and the postinfection-period applications (Fig. 2). Both types of applications, however, reduced disease significantly below the untreated control. For the protective applications, the level of control was statistically equivalent for applications made from 48 to $3 \mathrm{~h}$ prior to inoculation. The post-infection-period applications were most effective when applied soon after exposure to an infection event. Control declined as the time between the end of an infection period and a fungicide application increased; however, some level of control was obtained with applications made 24 or $48 \mathrm{~h}$ after the infection event.
Field study. Hourly weather and precipitation readings throughout each trial period are shown for all four plots in Figure 3. In New York, the conditions during inoculation and infection were highly favorable for disease development on 'Kent' with temperatures ranging between 22 and $30^{\circ} \mathrm{C}$. The conditions were less favorable during the inoculation of 'Jewel,' with a maximum high temperature of $18^{\circ} \mathrm{C}$. A minor rain event occurred after inoculation and just prior to the 24-h pyraclostrobin application in the long wetting regime of the Kent planting. Additional natural wetting occurred after treatments were applied (approximately $5 \mathrm{~mm}$ ), but prior to harvest in the Jewel planting. In Florida, temperatures were most favorable for infection and disease development in 2005. In 2004, a significant rain event occurred approximately 2.5 days after the $24-\mathrm{h}$ postinoculation fungicide application of pyraclostrobin. In this case, additional applications of pyraclostrobin were applied to the 4- and 24-h treatments as in the initial treatments. That is, the 4-h treatment received another application of pyraclostrobin $4 \mathrm{~h}$ after the rain had ceased, and the 24-h treatment received an application 24 $\mathrm{h}$ after the rain had ceased. The 8 -h treatment did not receive another application.

With one exception, the incidence of anthracnose in the untreated controls at both locations always was significantly greater than the incidence in the pyraclostrobintreated plots subjected to either a long or short wetting event (Fig. 4). The exception was in the 'Kent' planting for the 8-h postinfection treatments in the short and long wetting period regimes (Fig. 4A). In Flor-

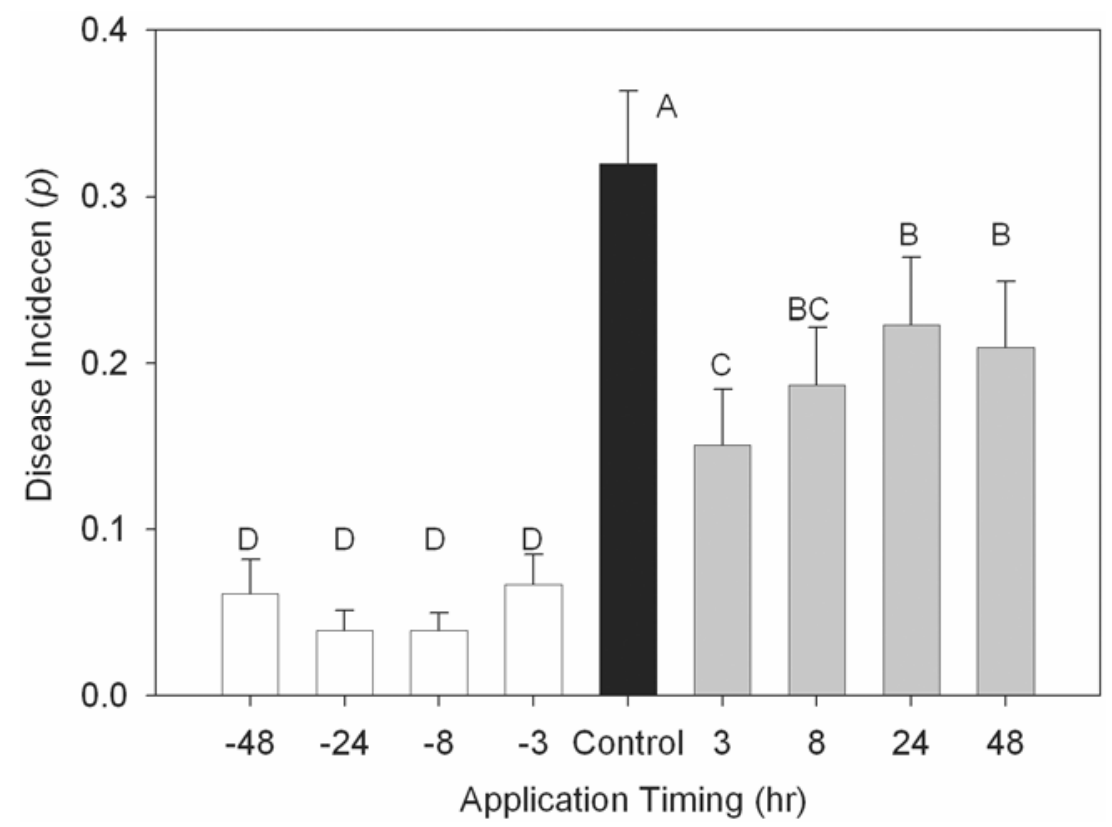

Fig. 2. Incidence and standard error of anthracnose on total strawberry fruit inoculated with Colletotrichum acutatum and treated with pyraclostrobin $3,8,24$, or $48 \mathrm{~h}$ before inoculation (bars with white background) or 3, 8, 24, or $48 \mathrm{~h}$ after inoculation (bars with gray background) and exposure to the wetting period in a laboratory experiment. Values represent means over the 12 temperature-wetting period durations. The black bar shows the incidence of anthracnose in the untreated, inoculated control. 
ida, post-infection-period treatments performed slightly better than the protective treatments in the planting of 'Camarosa', a highly susceptible cultivar (Fig. 4C). For the less susceptible cvs. Strawberry Festival (Florida) and Jewel (New York), preand post-infection-period treatments performed similarly under the short and long wetting period (Fig. 4B and D).

\section{DISCUSSION}

Results of this study clearly showed the high level of control that can be expected with post-infection-period applications of pyraclostrobin. Under controlled-climate conditions, post-infection-period applications provided significant control when made within $3 \mathrm{~h}$ and often up to $8 \mathrm{~h}$ after a wetting event, but generally were less effective than protective sprays. Under field conditions, the level of control was better than anticipated. With the exception of the 'Kent' planting, anthracnose fruit rot was managed to levels statistically equivalent to or less than that achieved with protective applications. In the Kent planting, conditions for disease development were exceptionally favorable and only postinfection-period applications applied at $4 \mathrm{~h}$ after the wetting event reduced disease incidence below that of the untreated control.

Most published guidelines for anthracnose management recommend that fungicides be applied on a calendar-based schedule. This is the most conservative approach for managing anthracnose and the one most widely adopted. Ideally, applications should be made only prior to significant wetting or rain events rather than on a calendar-based schedule. This recommendation is difficult to follow, particularly in the eastern United States, where wetting events during fruit set and harvest are associated with sporadic thun-
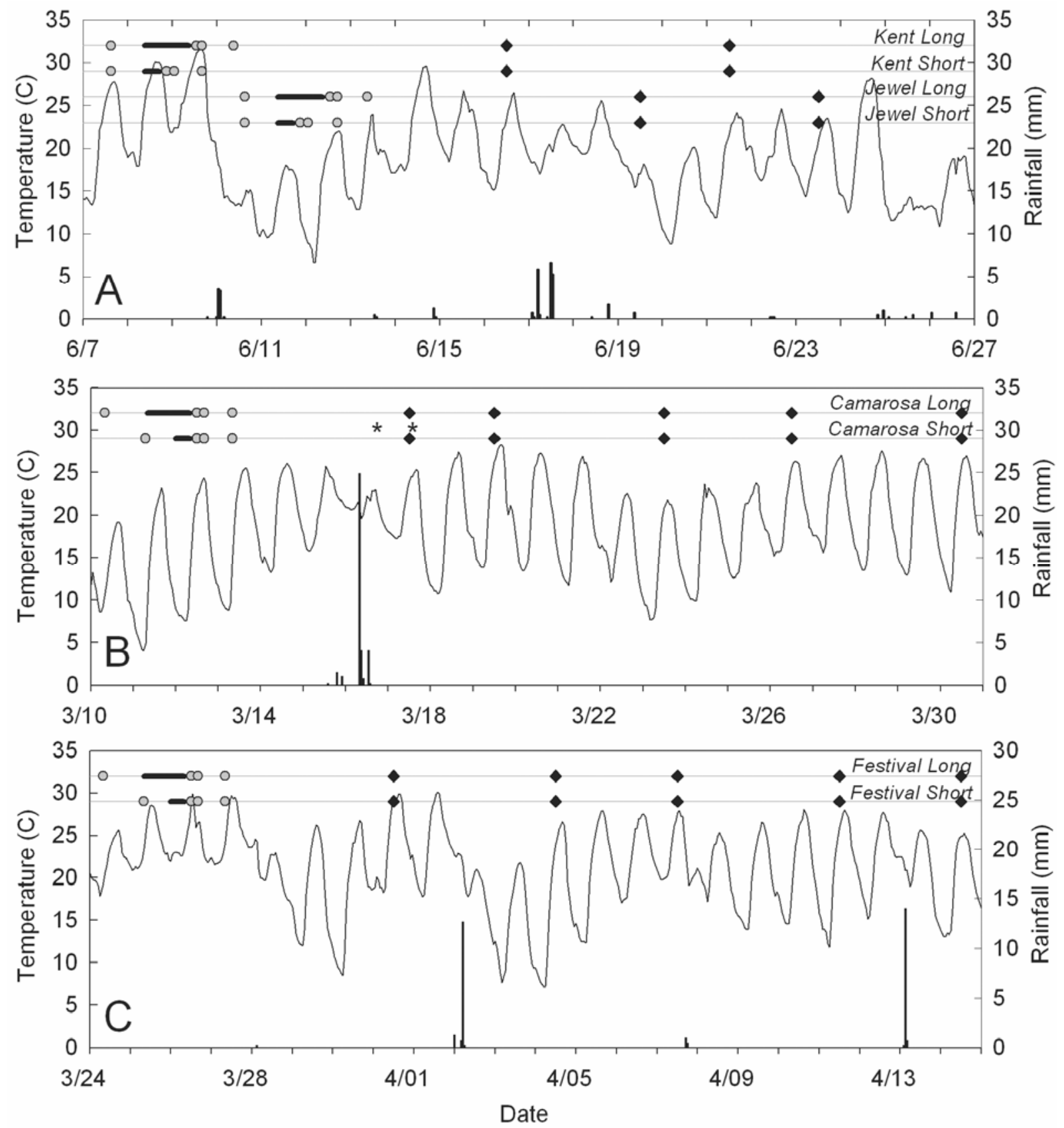

Fig. 3. Environmental conditions from inoculation through harvest for the field trials conducted in A, Geneva, NY (2004), B, Dover, FL (2004), and C, Dover, FL (2005). The solid line represents hourly temperature; the bars represent rainfall in millimeters. The duration of artificial wetting is shown as a thickened, horizontal black line for the variety and wetness duration (short or long) indicated on the figure. Inoculations occurred at the beginning. The shaded circles indicate the timings of fungicide applications. The filled diamonds represent harvest dates. The asterisks in $\mathbf{B}$ represent additional fungicide applications made in response to natural wetting. 
derstorms that are difficult to predict. Our study indicates that for short wetting events, such as those associated with seasonal thunderstorms, growers have the option of waiting until the wetting event occurs before applying pyraclostrobin and can expect to achieve control equivalent to a protective spray of pyraclostrobin when applied within $8 \mathrm{~h}$ of the end of the wetting event. For the most resistant cultivars (Jewel and Festival), post-infection applications could be made up to $24 \mathrm{~h}$ after the end of the wetting event. Over the course of a season, this approach likely would lead to fewer and better-timed fungicide applications, particularly in drier seasons.

The strobilurin fungicides act by inhibiting cellular respiration (1). Effectively, this prevents spore germination, making them excellent protective fungicides, and also offers curative activity (i.e., after infection but prior to symptom development) through the inhibition of mycelial growth (1). The strobilurins are not known to possess good antisporulant or eradicant activity. Given their activity, they generally are recommended to be applied just prior to or shortly after an infection (1). Applications made shortly after an infection event likely take advantage of the protective as well as the curative properties of the strobilurins, particularly for wetting events of short duration. This is because it is likely that many of the dispersed spores would not have germinated by the end of the wetting period. The post-infection activity demonstrated here is not unique to pyraclostrobin. Azoxystrobin, the only other strobilurin registered for use on strawberry, has a similar mode of action and would likely have comparable post-infection activity. However, in wheat and barley it has been shown that azoxystrobin is more effectively redistributed than pyraclostrobin, has greater mobility within xylem vessels, and exhibits translaminar movement (1). It is unknown if azoxystrobin shows similar behavior in strawberry or whether those properties adversely impact efficacy.

Additional choices for control of anthracnose are limited to treatments of the prepackaged mixture of fludioxonil and cyprodinil (Switch 62.5WG, as a 2(ee) recommendation in FL, MD, DE, VA, and WV) and the prepackaged mixture of Captan and Elevate (CaptEvate 68 WDG). Captan (Captan 80WDG) and thiophanatemethyl (Topsin-M 70WP) are labeled for use on strawberry and have activity against anthracnose, but are not labeled specifically for anthracnose. It is difficult to speculate on the post-infection activity of these fungicides based on results of this study, although it can be assumed that strictly protective fungicides, such as captan, will have no post-infection activity whereas other systemic fungicides will. We currently are evaluating the post-infection activity of other fungicides registered on strawberries. In citrus, post-infection applications of benomyl (similar to thiophanate-methyl) up to $48 \mathrm{~h}$ after inoculation reduced the severity of postbloom fruit drop, caused also by C. acutatum, although they did not reduce spore germination (23).

One of the risks associated with applying fungicides post-infection is acceleration of the development of fungicide resistance $(11,13,24)$. This has been shown to occur with demethylation-inhibiting (DMI) fungicides, for which the standard use of post-infection applications has been cited as the cause of sensitivity shifts and the development of resistance by the apple scab pathogen, Venturia inaequalis $(12,14,28)$. However, it is unclear if the rate at which resistance develops is a function of the elapsed time between the end of an infection event and the application of a fungicide. That is, will resistance develop at a slower rate if the application is made 8 versus $48 \mathrm{~h}$ after an event? It also is unclear whether reducing the total number of applications or amount of fungicide ap-
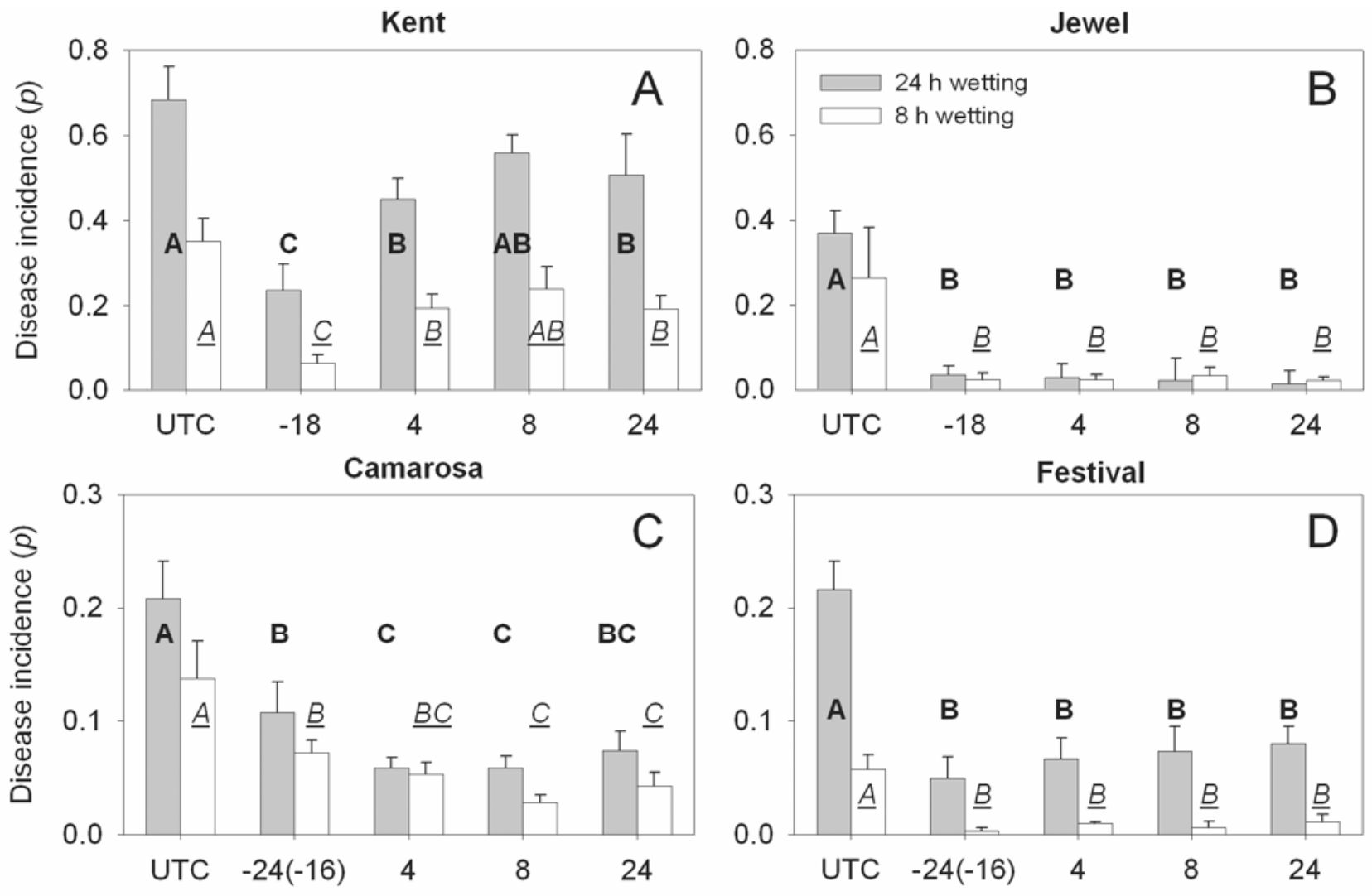

Application timing (hr)

Fig. 4. Incidence and the standard error of anthracnose in plots treated with pyraclostrobin 16 , 18, or $24 \mathrm{~h}$ before inoculation or 4 , 8 , and $24 \mathrm{~h}$ after exposure to a short ( $8 \mathrm{~h}$, hatched bars) or long ( $24 \mathrm{~h}$, solid bars) wetting period. A, 'Kent' grown in Geneva, NY (2004); B, 'Jewel' grown in Geneva, NY (2004); C, 'Camarosa' grown in Dover, FL (2004); and D, 'Strawberry Festival' grown in Dover, FL (2005). Treatments sharing the same letters and typeface are not significantly different from each other according to the $P D I F F$ option of PROC MIXED $(P=0.05)$. UTC $=$ untreated control. 
plied during the season, or reducing the number of applications used post-infection is more beneficial in delaying the development of resistance. These questions need to be addressed to improve recommendations for the post-infection use of fungicides with curative activity.

One of the benefits of applying fungicides post-infection is that fungicides are used only when necessary, which could reduce substantially the amount of fungicide applied in a season. A serious problem that growers have with "reactive" spraying is the short response time from the end of an infection event to the time when a fungicide must be applied to be as effective as a protective spray. Generally, growers are uncomfortable leaving their crop unprotected until an infection event has passed. Their major concerns are whether they can respond quickly enough after a rain event, whether the field will be drivable after the rain has fallen, and missing an infection event (e.g., when rainfall occurs during nighttime hours). Therefore, in some situations, a protective, calendar-based schedule is the appropriate choice. However, there clearly are instances where judicious applications are necessary (e.g., during picking, particularly in U-pick operations). The development of a forecaster that integrates our knowledge of the environmental conditions suitable for the development of anthracnose (30) with the knowledge of fungicide efficacy may give growers additional time to plan fungicide applications. In citrus, a forecaster for postbloom fruit drop, caused by $C$. acutatum, has been developed and widely adopted (22).

The strobilurin fungicides generally are considered the most effective materials against anthracnose fruit rot, particularly in the eastern and midwestern United States, although captan applied on a strict calendar spray schedule for gray mold control has been very effective for control of anthracnose in Florida $(17,21)$. In that state, Botrytis gray mold is a problem primarily during the cooler months of the production season (January and February), whereas anthracnose is more significant later in the season, when temperatures are warmer (March). If models are developed for both diseases, then fungicides with more specific activity against each disease could be applied at different seasons. Thus, routine, precautionary sprays with broad-spectrum fungicides could be avoided and a more targeted approach to disease management could be developed.

\section{ACKNOWLEDGMENTS}

This project was supported by funds provided by the United States Department of Agriculture Competitive Hatch Project and New York Ag \& Markets Specialty Crops Grants Program. We thank C. Heidenreich, G. Heidenreich, C. Torres, T. Seijo, and J. Mertely for their technical assistance; and two anonymous reviewers for the constructive comments.
LITERATURE CITED

1. Bartlett, D. W., Clough, J. M., Godwin, J. R., Hall, A. A., Hamer, M., and Parr-Dobrzanski, B. 2002. The strobilurin fungicides. Pest Manage. Sci. 58:649-662.

2. Eastburn, D. M., and Gubler, W. D. 1990. Strawberry anthracnose: Detection and survival of Colletotrichum acutatum in soil. Plant Dis. 74:161-163.

3. Eastburn, D. M., and Gubler, W. D. 1992. Effects of soil moisture and temperature on the survival of Colletotrichum acutatum. Plant Dis. 76:841-842.

4. Feil, W. S., Butler, E. E., Duniway, J. M., and Gubler, W. D. 2003. The effects of moisture and temperature on the survival of Colletotrichum acutatum on strawberry residue in soil. Can. J. Plant Pathol. 25:362-370.

5. Freeman, S., and Katan, T. 1997. Identification of Colletotrichum species responsible for anthracnose and root necrosis of strawberry in Israel. Phytopathology 87:516-521.

6. Freeman, S., Katan, T., and Shabi, E. 1998. Characterization of Colletotrichum species responsible for anthracnose diseases of various fruits. Plant Dis. 82:596-605.

7. Freeman, S., Shalev, Z., and Katan, J. 2002. Survival in soil of Colletotrichum acutatum and Colletotrichum gloeosporiodes pathogenic on strawberry. Plant Dis. 86:965-970.

8. García Muñoz, J. A., Suárez, M. B., Grondona, I., Monte, E., Buddie, A. G., Bridge, P. D., and Cannon, P. F. 2000. A physiological and biochemical approach to the systematics of Colletotrichum species pathogenic to strawberry. Mycologia 92:488-498.

9. Gunnel, P. S., and Gubler, W. D. 1992. Taxonomy and morphology of Colletotrichum species pathogenic to strawberry. Mycologia 84:157-165.

10. Howard, C. M., Maas, J. L., Chandler, C. K., and Albregts, E. E. 1992. Anthracnose of strawberry caused by Colletotrichum complex in Florida. Plant Dis. 76:976-981.

11. Ishii, K., Fraaije, B. A., Sugiyama, T., Noguchi, K., Nishimura, K., Takeda, T., Amano, T., and Hollomon, D. W. 2001. Occurrence and molecular characterization of strobilurin resistance in cucumber powdery mildew and downy mildew. Phytopathology 91:1166-1171.

12. Köller, W., Parker, D. M., Turechek, W. W., Avila-Adame, C., and Cronshaw, K. 2004. A two-phase resistance response of Venturia inaequalis populations to the QoI fungicide kresoxim-methyl and trifloxystrobin. Plant Dis. 88:537-544.

13. Köller, W., and Wilcox, W. F. 2001. Evidence for the predisposition of fungicide-resistant isolates of Venturia inaequalis to a preferential selection for resistance to other fungicides. Phytopathology 91:776-781.

14. Köller, W., Wilcox, W. F., Barnard, J., Jones, A. L., and Braun, P. G. 1997. Detection and quantification of resistance of Venturia inaequalis populations to sterol demethylation inhibitors. Phytopathology 87:184-190.

15. Leandro, L. F. S., Gleason, M. L., Nutter, F. W., Wegulo, S. N., and Dixon, P. M. 2001. Germination and sporulation of Colletotrichum acutatum on symptomless strawberry leaves. Phytopathology 91:659-664.

16. Legard, D. E. 2000. Colletotrichum Diseases of Strawberry in Florida. Pages 292-299 in: Colletotrichum: Host Specificity, Pathology, and Host-Pathogen Interaction. D. Prusky, S. Freeman, and M. B. Dickman eds. American Phytopathological Society Press, St. Paul, MN.

17. Legard, D. E., Mackenzie, S. J., Mertely, J. C., Chandler, C. K., and Peres, N. A. 2005. Development of a reduced use fungicide program for control of Botrytis fruit rot on annual winter strawberry. Plant Dis. 89:1353-1358.

18. Littell, R. C., Milliken, G. A., Stroup, W W., and Wolfinger, R. D. 1996. SAS Systems for Mixed Models. SAS Institute Inc., Cary, NC.

19. Maas, J. L., ed. 1998. Compendium of Strawberry Diseases, 2nd ed. American Phytopathological Society Press, St. Paul, MN.

20. Madden, L. V., Wilson, L. L., and Ellis, M. A. 1993. Field spread of anthracnose fruit rot of strawberry in relation to ground cover and ambient weather conditions. Plant Dis. 77:861866.

21. Mertely, J. C., Seijo, T. E., and Peres, N. A. 2005. Evaluation of fungicides to control anthracnose fruit rot in annual strawberry, 2003 04. Fungicide \& Nematicide Tests 60:SMF004. The American Phytopathological Society, St. Paul, MN.

22. Peres, N. A. R., Kim. S, Beck, H. W., Souza, N. L., and Timmer, L. W. 2002. A fungicide application decision (FAD) support system for postbloom fruit drop of citrus (PFD). Plant Health Progress doi: 10.1094 PHP-2002-073101-RV.

23. Peres, N. A. R., Souza, N. L., Zitko, S. E., and Timmer, L. W. 2002. Activity of benomyl for control of postbloom fruit drop of citrus caused by Colletotrichum acutatum. Plant Dis. 86:620-624

24. Sierotzki, H., Wullschleger, J., and Gisi, U. 2000. Point mutation in cytochrome $b$ gene conferring resistance to strobilurin fungicides in Erysiphe graminis f. sp. tritici field isolates Pestic. Biochem. Physiol. 68:107-112.

25. Smith, B. J. 1986. First report of Colletotrichum acutatum on strawberry in the United States. Plant Dis. 70:1074

26. Smith, B. J., and Black, L. L. 1990. Morphological, cultural and pathogenic variation among Colletotrichum species isolated from strawberry. Plant Dis. 74:69-76.

27. Turechek, W. W., Heidenreich, M. C., and Pritts, M. P. 2002. First report of strawberry anthracnose (Colletotrichum acutatum) in strawberry fields in New York. Plant Dis. 86:922.

28. Turechek, W. W., and Köller, W. 2004. Managing resistance of Venturia inaequalis to the strobilurin fungicides. Plant Health Progress doi:10.1094/PHP-2004-0908-01-RS.

29. Ureña-Padilla, A. R., Mitchell, D. J., and Legard, D. E. 2001. Oversummer survival of inoculum for Colletotrichum crown rot in buried strawberry crown tissue. Plant Dis. 85:750754.

30. Wilson, L. L., Madden, L. V., and Ellis, M. A. 1990. Influence of temperature and wetness duration on infection of immature and mature strawberry fruit by Colletotrichum acutatum. Phytopathology 80:111-116.

31. Wilson, L. L., Madden, L. V., and Ellis, M. A. 1992. Overwinter survival of Colletotrichum acutatum in infected strawberry fruit in Ohio. Plant Dis. 76:948-950.

32. Wise, K. A., Leandro, L. F. S., Wegulo, S. N., and Gleason, M. L. 2003. Survival and dispersal of Colletotrichum acutatum on strawberry foliage under field conditions. Adv. Strawberry Res. 22:14-19.

33. Yang, X., Wilson, L. L., Madden, L. V., and Ellis, M. A. 1990. Effect of surface topography and rain intensity on splash dispersal of Colletotrichum acutatum. Phytopathology 80:11151120 .

34. Yang, X., Wilson, L. L., Madden, L. V., and Ellis, M. A. 1990. Rain splash dispersal of Colletotrichum acutatum from infected strawberry fruit. Phytopathology 80:590-595. 